\title{
Oxidative stress associated with nematode infections in sheep: a preliminary study
}

\author{
Andrew H. SIWELA ${ }^{1 *}$, Chiedza Isabel MAMBVURA ${ }^{1}$, K.E. MASANGANISE ${ }^{2}$ \\ and S. DUBE ${ }^{1}$ \\ ${ }^{1}$ National University of Science and Technology, Department of Applied Biology and Biochemistry, P.O. Box \\ 939, Ascot, Bulawayo, Zimbabwe. \\ ${ }^{2}$ Veterinary Department, P. O. Box Ry 72, Raylton, Bulawayo, Zimbabwe. \\ *Corresponding author, E-mail: asiwela@nust.ac.zw
}

\begin{abstract}
A hundred and seven sheep slaughtered at the Cold Storage Company (CSC) in Bulawayo, were examined for nematode parasite infections using coporological methods. Direct smear and salt floatation methods were used to observe nematode parasite eggs. Nine sheep were found to be infested with nematode eggs only. Nine uninfected sheep were used as controls. Liver samples collected from the infected and noninfected sheep were used for assays of the antioxidant enzymes, glutathione peroxidase (GPX) and diphosphotriphosho-diaphorase (DTD) as well as the intermediary metabolic enzyme, succinate dehydrogenase (SDH). Lipid peroxidation was assayed by determining malondialdehyde (MDA) levels. Significantly higher GPX activities were observed in infected sheep when compared with non- infected sheep $(p<001)$. No difference in the activity of DTD was observed in both infected and non-infected sheep $(p>0.05)$. Parasitic infection resulted in significant reduction in SDH activity $(p<0.05)$ and significantly higher MDA levels $(p<0.01)$. This study suggests that parasitic infections induce oxidative stress.
\end{abstract}

(c) 2010 International Formulae Group. All rights reserved.

Keywords: Glutathione peroxidase, malondialdehyde, succinate dehydrogenase, nematode diphosphotriphospho-diaphorase, lipid peroxidation.

\section{INTRODUCTION}

The spectrum of intestinal helminth parasites infecting livestock in Zimbabwe and their prevalence has received extensive attention from various workers and the pathology of some has been reviewed (Chingwena et al., 2002; Moyo et al., 2003; Dube et al., 2004). Studies on the effect of the parasites on the host's antioxidant enzyme activity in Zimbabwe and elsewhere are few (Egwunyenga et al., 2003; Pal et al., 2005; Bello et al., 2000).
Parasites compete with their host for nutrients and they destroy tissues of the host as they migrate to their final habitats within the host. This damage may cause metabolic changes which are expressed in a variety of ways. Intestinal helminthes which include trematodes, cestodes and nematodes can bring about ill health in the infected host. Sheep in particular are prone mostly to nematode infection and to a lesser extent trematodes and cestodes. In Zimbabwe, Haemonchus placei, Cooperia pectinata, 
Cooperia punctata, Oesophagostomum radiutum, Trichostrongylus axei and Ostertagia ostertagi have been documented as infecting ruminants (Moyo et al., 2003).

Parasites cause inflammation when imbedding and penetrating tissues. Inflammation reactions are accompanied by generation of reactive oxygen species (Egwunyenga et al., 2003; Pal et al., 2005; Bello et al., 2000). Reactive oxygen species (ROS) include the super oxide radical $\left(\mathrm{O}_{2}{ }^{\circ}\right)$, hydroxyl radical $(\mathrm{OH})$ and hydrogen peroxide $\left(\mathrm{H}_{2} \mathrm{O}_{2}\right)$. These reactive oxygen species induce oxidative damage of macromolecules such as polyunsaturated fatty acids in membrane lipids, essential proteins such as enzymes and nucleic acids, especially DNA. The oxidative damage is deleterious to cell and may lead to senescence and cell death (Beyer et al., 1996). However, the cell is equipped with several antioxidant defense enzymes which protect the cell from oxidative damage, as long as generation of reactive oxygen species does not overwhelm the activities of the antioxidant enzyme activity. These enzymes include SOD which converts the super oxide radical $\left(\mathrm{O}_{2}{ }^{*}\right)$ to hydrogen peroxide; GPX and CAT which breakdown hydrogen peroxide to water; DTD which is deemed to protect against lipid peroxidation by the hydroxyl radical $(\mathrm{OH})$ as well as against oxidation of proteins and DNA (Ernster and Dallner 1995). The aim of this study was to determine the effect of intestinal helminthes on some antioxidant enzymes using physical examination and coporological evaluation of parasites eggs to determine infected and noninfected sheep.

\section{MATERIALS AND METHODS Parasitological analysis}

Sheep slaughtered at CSC abattoir in Bulawayo were used in this study. Faecal samples for parasitological examination were collected from the small intestines or rectum of the slaughtered sheep. Samples were placed in screw cap plastic bottles and transported to the laboratory in cooler boxes containing ice. Faecal egg counts were done using the salt floatation technique, as described by Thienpont et al. (1979) and Soulsby (1982) in order to determine animals not carrying helminth parasites. The method involved taking $2 \mathrm{~g}$ of faecal sample into a test tube, adding $21 \mathrm{ml}$ of water and the tube thoroughly shaken to mix the contents. The mixture was filtered using muslin cloth to discard the large debris particles and the resulting filtrate was centrifuged at $3000 \mathrm{~g}$ for 3 minutes to settle the heavier parasite eggs. The supernatant was discarded and the tubes re-filled with saturated salt solution and re-centrifuged for 2 minutes at $3000 \mathrm{~g}$ so as to float the nematode eggs in the solution whose specific gravity was between 1.10 and 1.20 (Thienpont et al., 1979; Urquhart et al., 1987). A glass rod was then used to transfer the floating eggs in the supernatant onto a microscope slide where they were viewed under both low and high power. Parasites were physically determined in the rumen and reticulum by visual inspection and enumerated. The controls were those animals in which there were no helminth parasites demonstrated by coporological examinations.

\section{Biochemical analysis}

Liver samples from infected and noninfected sheep were collected for enzymatic assays, alongside faecal samples for the purposes of determining parasite infected and non infected sheep. The samples were transported on ice in cooler boxes to the laboratory and kept at $-80{ }^{\circ} \mathrm{C}$ until they were required for assays. Liver samples from each animal infected with helminth parasite were thawed and homogenized with 5 volumes of $50 \mathrm{mM}$ potassium phosphate buffer $(\mathrm{pH} \mathrm{7})$ and centrifuged at $9000 \mathrm{~g}$ for 10 mins at $4{ }^{\circ} \mathrm{C}$. The supernatant was aliquoted and stored at $80{ }^{\circ} \mathrm{C}$ until required.

\section{DT-diaphorase assay}

DT- diaphorase activity was measured according to the method described by Lind et al. (1990), modified and adapted for a 96 well microplate reader in our laboratory. The reaction mixture was in a final volume of 200 
$\mu \mathrm{l}$ and a decrease in absorbance at $600 \mathrm{~nm}$ over 3 minutes at $30{ }^{\circ} \mathrm{C}$ was recorded. DTD activity was calculated using the extinction coefficient for DCPIP $\left(\epsilon=21 \mathrm{mM}^{-1} \mathrm{~cm}^{-1}\right)$.

\section{Glutathione peroxidase assay}

Scholz et al. (1981) after adapting the method for a 96 well microplate reader. The $\mathrm{H}_{2} \mathrm{O}_{2}$ was used as a substrate to determine selenium-dependent glutathione peroxidase (Se-GPX) activity and consumption of NADPH monitored at $340 \mathrm{~nm}$ over 3 minutes at $30{ }^{\circ} \mathrm{C}$ as described by Scholz et reaction mixture volume was $160 \mu \mathrm{l}$. Se-GPX activity was calculated using the coefficient extinction for NADPH $\left(\epsilon=6.22 \times 10^{3} \mathrm{M}^{-1} \mathrm{~cm}^{-1}\right)$.

\section{Lipid peroxidation assay}

Lipid peroxidation was measured by measuring MDA concentration according to the method of Draper and Hadley (1990). Tissue was homogenised in aqueous TCA and methanolic BHT and heated in a capped tubes in a boiling water bath for 30 mins. The cooled samples were centrifuged to remove particulate matter and absorbance read at 535 nm. Calculation of MDA was done using the coefficient of extinction for MDA $(\epsilon=1.5 \mathrm{x}$ $\left.10^{5} \mathrm{M}^{-1} \mathrm{~cm}^{-1}\right)$.

\section{Succinate dedrogenase assay}

A modified method of Ackrell et al. (1978) was used to assay SDH. The test solutions consisted of $3 \mathrm{ml}$ potassium phosphate buffer ( $\mathrm{pH} 7.4$ ) which was added to $1 \mathrm{ml}$ of $0.01 \%$ 2, 6 DCPIP solution and $0.5 \mathrm{ml}$ of the protein extract. To this mixture, $1 \mathrm{ml}$ of the substrate, O.IM sodium succinate was then added followed by addition of paraffin oil and the decrease in absorbance of 2,6 DCPIP was measured at $600 \mathrm{~nm}$. A blank lacking the enzyme was simultaneously run.

\section{Statistical analysis}

Results obtained were subjected to a statistical evaluation using Student's t test.

\section{RESULTS}

Based on egg counts and identification, nine sheep were infected by nematodes only. The effect of parasites on the activities of GPX, DTD, and SDH are shown in Figure 1:
Significantly higher GPX activities were observed in infected sheep when compared with non-infected sheep ( $\mathrm{p}<001)$. No differences in the activities of DTD were observed in both infected and non-infected sheep ( $p>0.05$ ). Parasitic infection resulted in significant reduction in SDH activity ( $\mathrm{p}$ $<0.05)$.

Figure 2 shows the effect of parasites on MDA levels. Infected sheep had significantly higher MDA levels than non-infected sheep ( $p$ $<0.01)$.

\section{DISCUSSION}

Gastrointestinal parasites cause marked production losses in farm animals throughout the world (Sykes, 1994) and their control is difficult because of their resistance to antihelmenthic drugs (Prichard, 1994; Waller, 1994). Infection of sheep by nematodes was demonstrated by the presence of eggs in faeces. Such non-mixed infections are not very common in animals (Anderson, 1992). The gastrointestinal parasites can cause shifts in metabolic or molecular function of the liver (Sies, 1986; Sykes, 1994).

Infected sheep had higher GPX activity indicating that the sheep were under oxidative stress due to the infection. GPX is important in the detoxification of peroxides in the various cells and/or tissues of the animals. However, these results are in contrast to some studies of Stocker et al. (1985) suggesting that parasitism of mouse erythrocytes by Plasmodium vinkei results in a decrease in GPX activity and studies using fish (Neves et al., 2000). We speculate that parasite metabolic products could be generating ROS species in infected animals. Further, ROS could result from activated macrophages. Hydrogen peroxide, for example, is produced against the parasite by macrophages. Hydrogen peroxide is very stable and freely crosses the membrane and produces the reactive hydroxyl radical when it reacts with haeme proteins according to the Fenton reaction (Oliveira and Cecchini, 2000). 


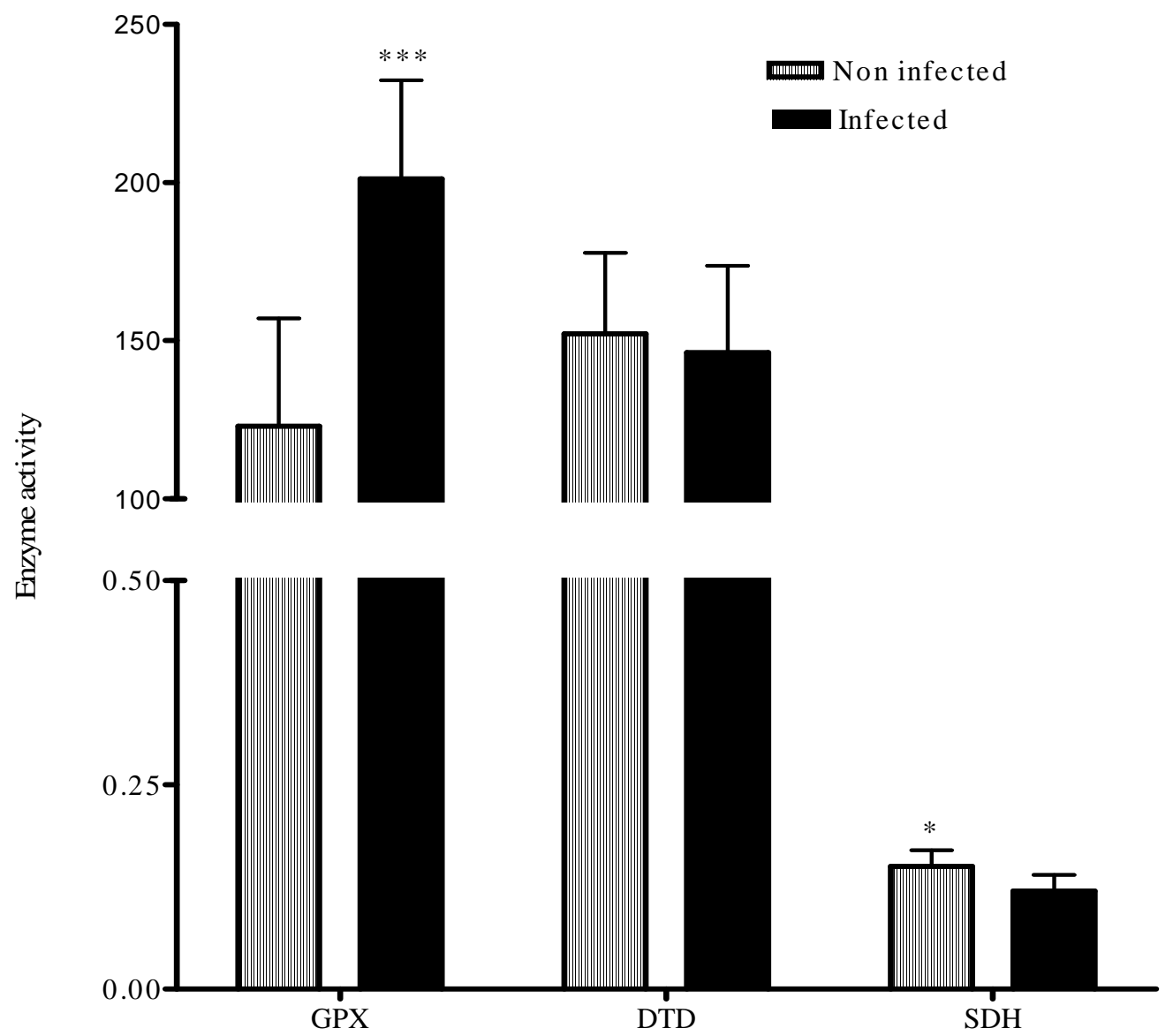

Fig 1. A comparison of enzyme activities in livers of non-infeceted and infected sheep. Values are means \pm SD from 7 non-infected sheep and 9 infected sheep. $* p<0.01$ and $* * * p<0.001$ significantly different from non-infected, Student's t test.

The similar DTD activity observed in non-infected and infected animals is rather puzzling given that higher levels of MDA - a product of lipid peroxidation- was observed in infected animals. DTD is an antioxidant enzyme that prevents initiation of lipid peroxidation (Halliwell and Gutteridge, 1989). The higher MDA levels in infected animals indicate that parasitism leads to oxidative stress. Our MDA results are in agreement with studies that have found significantly increased levels of MDA in serum of human patience with fascioliasis when compared to controls (Kaya et al., 2007) and human patients with falciparum malaria (Egwunyenga et al., 2004).

As parasitism has been reported to induce higher oxygen and energy consumption e.g. in fish (Anderson, 1975; Lemly and Esch, 1984), we decided to investigate the activity of SDH in liver mitochondria of infected and non-infected sheep. Higher SDH activity $(p>0.05)$ was observed in non-infected sheep suggesting a relatively lower metabolic rate in the infected animal. As SDH is a membrane bound enzyme, the lower activity could result from peroxidation of lipid membranes which in turn results from the alteration of the native 


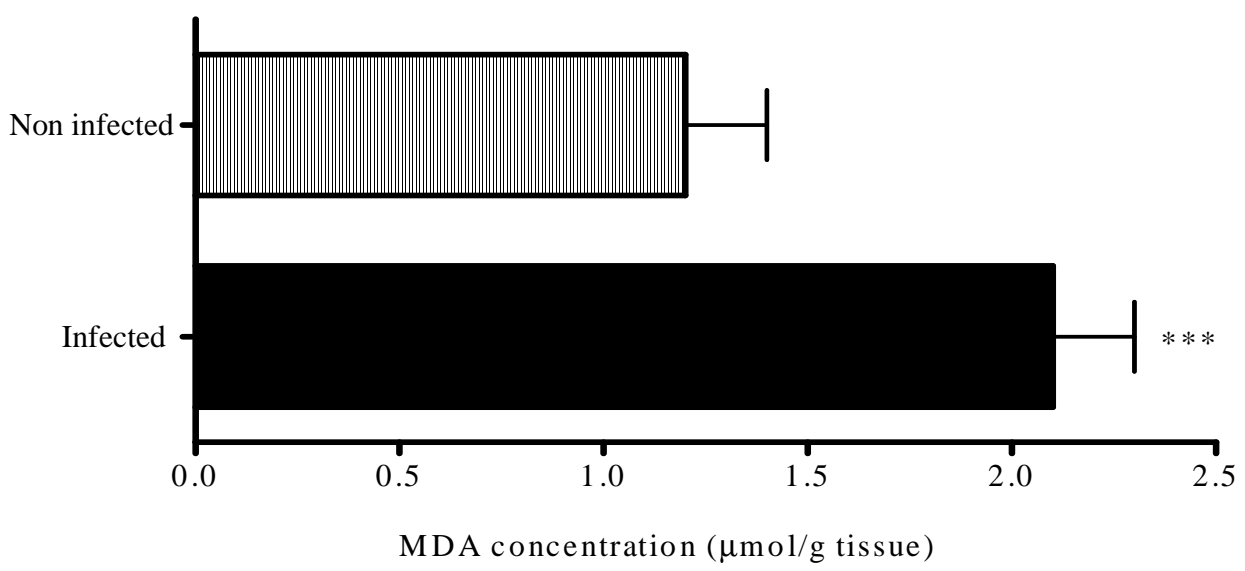

Fig 2. A comparison of MDA concentration in livers of non-infected and nematode infected sheep. Values are means \pm SD from 7 non-infected and 9 infected sheep. $* * * p<0.001$ significantly different from non-infected animals, Student's t test.

conformation of the membrane-bound proteins.

Overall, the present study indicated that parasites significantly increased lipid peroxidation as shown by increased MDA levels in infected sheep whilst increasing the activity of GPX.

\section{ACKNOWLEDGEMENTS}

This work was supported by funds from Research Board, National University of Science and Technology, Zimbabwe. The authors wish to thank the Cold Storage Company, Bulawayo, for allowing them to collect samples.

\section{REFERENCES}

Ackrell BA, Kearney CE, Singer, TB. 1978. Mammalian succinate dehydrogenase. In Biomembranes, Fleischer S, Parker L (eds). Acadenic Press: NY; 466-483.

Anderson RC. 1992. Nematode Parasites of Vertebrates: their Development and Transmission. CAB International, Wallingford; 1-5.

Anderson, G. 1975. Metabolic response of the caridean shrimp Paleomonete pugio to infection by the adult epibranchial isopod parasite Probopyrus pandalicola. Comp. Biochem. Physiol., 52: 201-207.
Bello ARR, Fortes E, Bello-Klein A, Bello AA, Llesuy SF, Rabaldo RB, Bianchini A. 2000. Lipid peroxidation induced by Clinostomum detruncatum in muscle of the fresh water fish Rhamdia quelen. Dis. Aquatic Org., 42: 233-236.

Chingwena GS, Mukaratirwa S, Kristensen TK, Chimbari M. 2002. Susceptibility of freshwater snails to amphistome Calicophoron microbothrium and the influence the species on susceptibility of Bulinus tropicus to Schistosoma haematobium and Schistosoma mattheei infections J. Parasitol., 88: 880-883.

Draper H., Hadley M. 1990, Malondialodehyde determination as an index of lipid peroxidation Methods Enzymol., 186: 421-4312.

Dube S, Siwela AH, Masanganise KE, Dube, C. 2004. Abattoir studies on paramphistomes recovered from cattle from Masvingo and Manicaland provinces of Zimbabwe. Folia Vet., 48: 123-129.

Egwunyenga AO, Isamah G, Nmorsi P. 2004. Lipid peroxidation and ascorbic acid levels in Nigeria children with acute falciparum malaria. Afr. J. Biotech., 3: 560-563. 
Ernster L, Dallner G. 1995. Biochemical, physiological and medical aspects of ubiquinone function. Biochem. Biophys. Acta., 1271: 195-204.

Halliwell B, Gutteridge JMC. 1989. Free Radicals in Biology and Medicine. Claredon Press: Oxford.

Kaya S, Sutcu E, Certin E, Aridogan, BC Dermici M. 2007. Lipid peroxidation level and antioxidant enzyme activities in the blood of patients with acute and chronic fascioliasis. Int. J. Infectious Dis., 11: 251-255.

Lemly D, Esch MJ. 1984. Platelminta. In Elementos de Ictoparasitologia, de Almeida A (ed). Fundacao Eng: Porto.

Lind C, Cadenas E, Hochstein P, Ernster L. 1990. DT diaphorase purification. Methods Enzymol., 186: 287 -301.

Moyo DZ, Hendrikx WML, Obwolo L.Eysker M. 2003. The effect of treatment with $1 \%$ injectable formulation of Moxidectin during the rainy season and at the beginning of the dry season on gastrointestinal nematodes in cattle from communal areas on Zimbabwe. Tropical Animal Hlth Prod., 35: 1-16.

Oliveira F, Cecchini R. 2000. Oxidative stress of liver hamsters infected with Leishmania (L) chagasi. J Parasitol., 86: 1067-1072.
Pal, B.K. Kulkarni, S., Bhandari, Y., Balaji, B. Ganesh, K., Goswami, K and Reddy, M.V.R. 2005. Lymphatic filariasis: possible pathophysiological nexus with oxidative stress. Trans. Royal Soc. Tropical Med. Hygiene 100: 650-655.

Thienpont D, Rochette F, Vanparijs OFJ. 1979. Diagnostic Helminthiasis through Coporological Examination. Janssen Research Foundation: Beerse, Belgium.

Scholz RW, Cook LS, Todhunter DA. 1981. Distribution of selenium dependent and non- selenium dependent glutathione peroxidase activity in tissue of young cattle. Am. J. Vet. Res., 42, 1724-1729.

Sies H. 1986. Biochemistry of oxidative stress. Angew Chem Int. Engl.25: 10581071.

Soulsby JD. 1982. Helminths, Arthropods and Protozoa of Domesticated Animals. Balliere Tindall: London.

Sykes AR. 1994. Parasitism and production in farm animals. Animal Production. 59: 155-172.

Urquhart GM, Armour J, Duncan JL, Dunn AM, Jennings FW. 1987. Veterinary Parasitology. Longman Scientific and Technical: London. 